\title{
An econometric analysis of cognitive impairment and healthcare utilization in the ageing population
}

DOI:

10.1080/00036846.2018.1486996

\section{Document Version}

Accepted author manuscript

Link to publication record in Manchester Research Explorer

\section{Citation for published version (APA):}

Gannon, B., Banks, J., Nazroo, J. Y., \& Munford, L. (2018). An econometric analysis of cognitive impairment and healthcare utilization in the ageing population. Applied Economics.

https://doi.org/10.1080/00036846.2018.1486996

\section{Published in:}

Applied Economics

\section{Citing this paper}

Please note that where the full-text provided on Manchester Research Explorer is the Author Accepted Manuscript or Proof version this may differ from the final Published version. If citing, it is advised that you check and use the publisher's definitive version.

\section{General rights}

Copyright and moral rights for the publications made accessible in the Research Explorer are retained by the authors and/or other copyright owners and it is a condition of accessing publications that users recognise and abide by the legal requirements associated with these rights.

\section{Takedown policy}

If you believe that this document breaches copyright please refer to the University of Manchester's Takedown Procedures [http://man.ac.uk/04Y6Bo] or contact uml.scholarlycommunications@manchester.ac.uk providing relevant details, so we can investigate your claim.

\section{OPEN ACCESS}



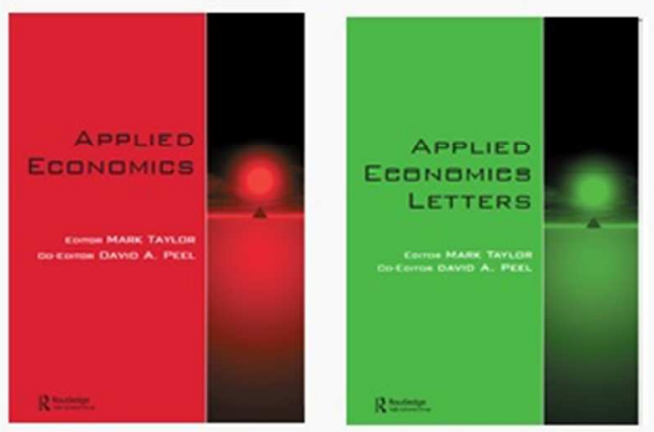

\section{An Econometric Analysis of}

\section{Cognitive Impairment and Healthcare Utilisation in the}

\section{Ageing Population}

\begin{tabular}{|r|l|}
\hline Journal: & Applied Economics \\
\hline Manuscript ID & APE-2017-0196 \\
\hline Journal Selection: & Applied Economics incorporating Applied Financial Economics \\
\hline Date Submitted by the Author: & $09-$ Mar-2017 \\
\hline Complete List of Authors: & $\begin{array}{l}\text { Gannon, Brenda } \\
\text { Banks, James; University of Manchester, Economics } \\
\text { Nazroo, James; University of Manchester } \\
\text { Munford, Luke }\end{array}$ \\
\hline JEL Code: & $\begin{array}{l}\text { I10 - General < I1 - Health < I - Health, Education, and Welfare, C10 - } \\
\text { Mathematical and Quantitative Methods }\end{array}$ \\
\hline Keywords: & healthcare, ageing, cognitive impairment, panel \\
\hline
\end{tabular}

\section{SCHOLARONE ${ }^{\text {m }}$}

Manuscripts 


\title{
An Econometric Analysis of
}

\section{Cognitive Impairment and Healthcare Utilisation in the Ageing Population}

March 7, 2017

\begin{abstract}
The ageing population is a major concern for policy makers, with the ever-increasing strains placed on health budgets. One overlooked area of research is the impact that cognitive impairment (an early marker of potential dementia onset) has on the healthcare utilisation of an ageing population. Based on the theoretical micro-economic foundations of health care demand, we study the relationship between cognitive functioning and impairment, measured by word recall and changes thereof, and healthcare utilisation among over 50s in nine European countries. The contribution of this paper is to produce estimates for cognitive functioning and impairment, as opposed to full dementia, in the context of health care utilisation.

We apply regression models to health care utilisation data from Waves 1, 2, and 4 of the Survey of Health, Ageing and Retirement in Europe (SHARE) and find that recalling one additional word is associated with a reduction in visits to a medical doctor of 0.32 , per year $(p<0.01)$. Even after controlling for self-assessed health, this association is strong at just over 0.1 visits - this is the additional impact, over and above the average number of visits for similar individuals without cognitive impairment.
\end{abstract}

Key Words: Healthcare utilisation; Ageing Population; Cognitive Impairment

JEL:

\footnotetext{
* The data used are taken from SHARE; please see the data section for acknowledgement.
} 


\section{Introduction}

The aim of this paper is to assess the association between cognitive impairment and health care utilisation, to determine if lower cognitive impairment is related to higher or lower use of health care services, among older people in Europe. The ageing population is an important driving factor in changing the emphasis of health service delivery. One such example is moving from acute care in hospitals to community care for long-term health conditions, such as dementia. Currently, the global cost of dementia stands at US€604 billion, amounting to 1-2\% of GDP in developed countries (World Alzheimer Report, 2012). While this condition alone is a large strain on resources, it has also been recognised that impaired cognitive status is a hallmark of dementia and recent research shows that cognitive decline may begin much earlier than expected, with onset often occurring at middle age (Singh-Manoux et al., 2012). The impact of cognitive decline is emphasised further in people with co-morbidities, such as hypertension and diabetes (Kawamura et al. 2012). It is not surprising therefore that health care policy now puts cognitive decline and dementia at the forefront of the health agenda.

The cognitive status of an ageing population has received much coverage by economists in recent years. For example Bonsang et al. (2012) and Mazzonna and Peracchi (2012) look at how cognition determines, and is determined by, retirement decisions. Interestingly, there is very little empirical evidence in economics to date on use of healthcare by people with cognitive impairment, as opposed to fully diagnosed dementia. The contribution of this paper therefore is to build on this research by including longer term panel data from several European countries and to include socio-economic variables that are relevant to health economic theory. Furthermore, we focus specifically on cognitive impairment, as opposed to diagnosed dementia or Alzheimer's Disease. Hence, we include all of the population aged 50 and over, and their measurement of cognitive functioning. Our measure is a standardised one, word recall, but is not a proxy for dementia status.

As far as we are aware, this is the first empirical study that attempts to quantify the relationship between cognitive impairment and health care use, based on the Grossman model theoretical framework. We use the typical health production theoretical framework (Grossman, 1972) to develop our hypothesis for our empirical models: an individual gains utility $u$ from a stock of health, $H$, and the consumption of a bundle of other commodities, $C$. The demand for medical care depends on a simple process whereby an additional unit of $H$ requires $\theta$ units of medical care ${ }^{1}$. We avoid further technical detail here, and recommend interested readers to view Jack (1999) [ch4] and Grossman

\footnotetext{
${ }^{1}$ In this simplistic framework, $\theta$ can be thought of as a natural index of the health state of the individual; the higher $\theta$ is then the sicker the individual is.
} 
1

2

3

4

5

6

7

8

9

(1972). The aim of our analysis here is to see how cognitive status, proxied by word recall (WR), affects the medical utilisation variable $\theta$. A priori, we expect individuals with better cognitive status to make fewer visits to healthcare professionals, such that we expect the partial derivative $\partial \theta / \partial W R<0$. This is due to the fact that poor cognitive status can be thought of as a marker of poor mental health and/or dementia (Singh-Manoux et al., 2012), and as such people with lower levels of mental health are more likely to have a higher demand (or need) for the services of medical doctors. However, there is also a possibility that those individuals with lower cognition are less likely to be able to fully understand their health conditions as a person with higher cognitive status (ceteris paribus) and hence may not utilise healthcare as often as they should. Therefore the exact sign of the relationship is ambiguous and hence we wish to test this hypothesis.

We use a rich source of European data, SHARE (Survey of Health Ageing and Retirement in Europe) that follows individuals from 2004 and onwards, as these data contain relevant data on health care resource utilization among other variables. Similar datasets exist in the US and England (Health and Retirement Survey and English Longitudinal Study of Ageing), but focus on the US or do not include health care utilization respectively. The variation in health systems in Europe makes the SHARE data an interesting source of information and we also will focus on the impact of various types of health systems. We first examine the cognitive trajectories of a number of age cohorts within Europe, applying empirical models to SHARE. We observe a fall in cognitive status as individual's age, and we observe that older cohorts perform, on average, less well than their younger counterparts. Within cohorts, females outperform males, and education (especially at university level) increases cognitive status. We then examine how cognitive status affects healthcare utilisation within Europe, and observe a negative, and often statistically significant, relationship; implying individuals with lower levels of cognition make more visits to medical doctors. This negative association is robust to a number of potential country groupings within the European countries. Our results are the first attempt to provide the correlations between cognitive impairment and health care use and are of interest in their own right to European health and ageing policy. We also control for unobserved heterogeneity in our models by exploiting the panel nature of the data, and hence move closer to providing a causal effect compared to that provided by a standard statistical associative model.

\section{Materials and Methods}


The main data source for our analysis is waves 1, 2, and 4 of the Survey of Health, Ageing and Retirement in Europe (SHARE) ${ }^{2}$. SHARE is a unique cross-European interdisciplinary data set containing a rich source of information relating to the lives of over 50 year olds. Wave 1 contains information from 2004 and each successive wave is carried out two years apart, such that wave 4 relates to 2010. We do not use data from wave 3 (2008) as this was predominantly a retrospective life history module, and as such did not contain sufficient information. Our analysis is based on individuals in nine European countries: Austria; Belgium; Denmark; France; Germany; Italy; the Netherlands; Spain; and Switzerland. SHARE gives a broad picture of life after age 50, measuring physical and mental health, both objectively and subjectively; life satisfaction and well-being; and also contains a broad range of socioeconomic information. We now outline the key variables from SHARE that we use in our analysis.

Within SHARE, individuals are asked about their health care utilisation. The key question(s) are: "How often seen or talked to medical doctor in the last 12 months". Individuals who report positive values to this question are then asked: "how many of these contacts were with a general practitioner $(G P)$ ". Individuals are also asked the number of times that they have been a patient in a hospital. ${ }^{3}$ The distribution of the overall number of visits to a medical doctor and the distribution of GP visits are presented in Figure 1(a). Table 2 provides the accompanying descriptive statistics.

Figure 1 here

Table 2 shows that the maximum number of visits, per year, is 98, and these visits comprise completely of visits to a GP. The number of visits to a hospital has a maximum at ten. The average number of medical visits is 7.3 (with a standard deviation of 10), and of these 5.14 are visits to a GP (with associated standard deviation of 7.7). The average number of visits to a hospital is on average 0.23 per year (this includes those who make zero visits).

Our key measure of cognitive functioning is the number of words an individual can recall (from a list of ten). The main variable of interest is the initial recall, although the individual is also asked to recall the same list of words after a short delay ${ }^{4}$. Using word recall as a proxy for cognition is common in the economics literature (e.g. Bonsang et al., 2012; Mazzonna and Peracchi, 2012), and

\footnotetext{
${ }^{2}$ This paper uses data from SHARE wave 4 release 1.1.1, as of March 28th 2013. The full disclaimer is available online at http://www.share-project.org/data-access-documentation/research-data-center-data-access.html

${ }^{3}$ A further question asks if an individual has had contact with a specialist doctor; although this is coded as a yes/no question, and hence we do not make further use of this in our analysis here.

${ }^{4}$ This delay is typically 10 minutes, during which time other questions are asked.
} 
1

2

3

4

5

6

7

8

9

hence we use this as our key explanatory variable ${ }^{5}$. The correlation between the initial and delayed word recall is $0.74(\mathrm{p}=0.00)$, implying a strong, and statistically significant, correlation between the two recalls. However, the average initial word recall (4.85) is larger than the delayed recall (3.44) with $t$ stat $=201.56,(\mathrm{p}=0.00)$.

Given that the SHARE data contains information on a number of different countries, the results from a pooled analysis may not be too informative due to the marked difference in a number of possible confounding factors across Europe ${ }^{6}$. We therefore consider a number of possible country groupings that is we group countries by observable characteristics. We grouped countries under three different categories, I - GP as Gatekeeper (Denmark, France, Italy, Netherlands, Spain) - II Funding systems (Austria, Belgium, Denmark, France, Italy, Spain) III - provision of informal care (Austria, Denmark, France, Switzerland)

Table 1 provides summary statistics for the key variables in our analysis. The average person makes around 7 visits to a medical doctor per year, with around 5 of these visits being to a GP. The average number of times spent in a hospital is 0.23 (note, however that this average contains a large amount of zeros $(n=37,719)$. Conditional on at least one visit, the average number of hospital visits in 1.57 $(\mathrm{n}=6,592))$. The average word recall (at the first recall) is around 5/10, which drops to 3.4 after a delay. There is a larger variation associated with the delayed recall, when compared to initial recall.

The average age of our sample is 66 , with age ranging between 50 and $104.45 \%$ of the individuals are male, and the average household comprises of 2 people. 19\% have university education (or higher), $50 \%$ have school or college level education, with the remaining $31 \%$ having no education (defined as leaving school with no qualifications/not attending compulsory schooling). Consistent with the literature on self-assessed health (SAH), the majority of the observations are in excellent $(10 \%)$ very good $(23 \%)$ and good $(37 \%)$. Only $7 \%$ report being in poor health, with $23 \%$ of individuals stating their health is fair.

\section{Table 1 here}

As a descriptive tool, we first plot trajectories of word recall, based on age and date of birth (DoB) cohort. We estimate the equation:

\footnotetext{
${ }^{5}$ There are more detailed memory indices in ELSA, however these are not contained in SHARE.

${ }^{6}$ Even after including country specific indicator variables, and the interaction of these variables with word recall.
} 


$$
W R_{i}=a+b\left(\text { Cohort }_{i}\right)+c\left(\text { age }_{i}\right)+d\left(\text { age }_{i}^{2}\right)+\mu_{i}
$$

where WR is word recall, Cohort is a date of birth cohort dummy variable ${ }^{7}$, age and age $e^{2}$ are age and it's square. We then obtain the predicted value of WR, and plot this over a range of ages in Figure 2.

Figure 2

The top left panel of Figure 2 shows that, on the whole, there is a negative relationship between age and word recall, implying that individuals can recall fewer words as they age. These trajectories accelerate downwards as people age; that is the slope of these functions are steeper for the older age cohorts. However, the trajectory of the oldest cohort actually lies above that of the second youngest, which is slightly surprising given all of the other trajectories are in descending order. There is some suggestion that the youngest cohort's word recall increases as they age, but this increase is small, and this effect is only true for those born after 1950. The top middle panel of Figure 2 adds in the confidence intervals (CIs) for these trajectories, and from this we can see that there is evidence of 'cohort effects' in that the CIs do not overlap for the different trajectories. Interestingly, at older ages there is a suggestion that individuals aged 80 in the second oldest cohort have similar word recall as 88 year olds in the oldest cohort.

The top right panel of Figure 2 examines the possibility of differential impacts across gender. We observe that females have, on average, better word recall, consistent across all ages and cohorts. This difference is statistically significant for the youngest four cohorts (bottom left panel), but for the oldest age cohort we observe overlapping CIs and hence conclude there is no evidence of a gender gap. However, for the younger ages we do observe females outperforming males when it comes to cognition.

It is often argued that educational attainment is a good predictor of cognition in later life (e.g. Evans et al., 1993; Christensen et al., 1997). Therefore, we repeat this trajectory analysis and condition on three levels of education (these are: (i) no or low; (ii) school or college level qualifications; and (ii) university (or equivalent) or higher level qualification). In the bottom middle panel of Figure 2, we show, as expected, those with higher levels of education do better than those with low levels. From this panel we can observe some interesting comparisons; for example the (expected) cognition of a 70 year old with no/low levels of education is the same as that for a 90 year old individual with university level education. For statistically significance differences (bottom right panel), on the

\footnotetext{
${ }^{7}$ We consider five date of birth cohorts. These are: (i) born $<1920$; (ii) $1920 \leq$ born 1930; (iii) $1930 \leq$ born 1940 ; (iv) 1940 $\leq$ born $<1950$; and (v) born $\geq 1950$.
} 
1

2

3

4

5

6

7

8

9

whole we only observe differences between university or above education and the rest - we cannot reject the hypothesis that no/low educated individuals have the same cognitive status as school/college educated people, as their CIs always overlap.

We then test our hypothesis, namely that those with lower cognitive status are more likely to use the health care resources more frequently, with estimation of the following empirical model:

$$
y_{i j}=\alpha W R_{i j}+\boldsymbol{\beta} \mathbf{X}_{i j}+\gamma S A H_{i j}+\varepsilon_{i j}
$$

where $y$ is the number of times an individual has visited a medical doctor ${ }^{8}$ in the past year, $W R$ is the number of words an individual correctly recalled without delay ${ }^{9}, \mathbf{X}$ is a matrix of observable characteristics, and $S A H$ is the self-assessed health. All variables refer to individual $i$ in country/country-group $j$. Finally $\varepsilon_{i j}$ is a stochastic error term whose distribution depends on the exact modelling strategy undertaken.

We estimate two models. We start by estimating model (1) using a pooled cross-section of SHARE data, and correcting for repeated observations across individuals by clustering the standard errors. We do this using both standard OLS, and count-data methods (in which case we assume $\varepsilon_{i j}$ has a negative binomial (NB) distribution) ${ }^{10}$.

However, if we assume that individual specific unobservable factors may influence the demand for health care then we should account for this in our econometric strategy. We do this by estimating Model (2):

$$
y_{i j t}=\alpha W R_{i j t}+\boldsymbol{\beta} \mathbf{X}_{i j t}+\gamma S A H_{i j t}+u_{i}+v_{i j t}
$$

where subscript $t$ refers to time. The main difference between (2) and (3) is that the error term is broken down into an individual specific component $\left(u_{i}\right)$ and a time-varying component $\left(v_{i j t}\right)$. We estimate (3) using both random-effects (REs) and fixed-effects (FEs) for both OLS and NB models. It is often the case that FEs are preferred over REs (when tested using a Hausman test (Hausman, 1978)), however, as we will see later, due to the time invariant nature of many of our control variables we predominantly use RE specifications here. For pooled NB models we present marginal

\footnotetext{
${ }^{8}$ The main utilisation variable we focus on is overall visits to a medical doctor. However, we also look at visits specifically to a GP.

${ }^{9}$ We also repeat this analysis for delayed word recall, and the average of immediate and delayed. For reasons of brevity however, we concentrate on initial word recall here. Results for the other two measures are available on request.

${ }^{10}$ We prefer the NB model over the Poisson model in all cases, indicating the existence of over dispersion. For technical details on count data models, see inter alios Greene (2008) [ch. 25.5] and (Cameron and Trivedi 2005) [ch. 20].
} 
effects. However, for the panel data NB model we present only the coefficient as the marginal effects requires us to specify the value of certain covariates. The default in Stata is to use the mean of the covariates, which gives the same value as the coefficient ${ }^{11}$.

\section{Results and discussion}

We start by describing the correlations between word recall and healthcare utilisation. All results presented here are for overall visits to a medical doctor ${ }^{12}$, and the key explanatory variable is initial word recall ${ }^{13}$. The correlation between initial word recall and overall health care visits is -0.1302 and statistically significant.

We first examine the association between word recall and healthcare utilisation for the pooled sample $^{14}$. Table 3 presents the results for all models where we control for age, gender, education, household size, country identifiers (Austria is the omitted reference country) and the interactions between word recall and the country identifiers. We also estimate the same models including age squared, but the results remain essentially the same, with age squared being negative and significant in most models. In Table 2 we present only the coefficient on word recall ${ }^{15}$.

Table 2 here

Column 1 presents the results from the basic OLS specification. We show that individuals that recall one more word, ceteris paribus, make 0.32 fewer visits to a medical doctor per year. Column 2 presents the pooled NB coefficient and column 3 contains the associated marginal effect. Focussing on the marginal effect, we see that those who recall one extra word have reduced visits to a doctor by 0.3 per year. It is worth observing here that the pooled OLS coefficient and the pooled NB marginal effect are essentially the same (to 1 d.p.). In columns 4 and 5 we include random-effects (RE), with RE-OLS (column 4) indicating a reduction of 0.24 visits per year whereas the coefficient of the RENB model (column 5) is considerable lower, indicating a reduction of only 0.01 visits a year. Finally

\footnotetext{
${ }^{11}$ We have looked at the marginal effects for different ages, but as they are too many to include here we present only the estimated coefficient.

${ }^{12}$ With one exception - when we consider the effect of GP gatekeeping on healthcare utilisation.

${ }^{13}$ Results for GP visits, hospital visits, and delayed word recall are available on request.

${ }^{14}$ To account for repeated observations across individuals we cluster standard errors at the individual level.

${ }^{15}$ Full output of all results is available on request.
} 
column 6 presents the results from fixed-effects (FE) OLS, where we observe a 0.1 reduction in healthcare utilisation associated with an increase in word recall of one word. It is worth noting that using FEs as opposed to REs limits the number of explanatory variables we can use, this is due to a large number of time-invariant regressors included in our models. All of the results above are statically significant $(\mathrm{p}<0.05)$.

The limitation of Table 2 is that we do not control for an individual's underlying health state; we could just be capturing the healthcare utilisation of people with poorer health. In order to overcome this, we further include SAH as a regressor. Results are shown in full in Table 3. This provides us with an indication of the additional impact of cognitive impairment, over and above that of poor health. Inclusion of SAH significantly reduces the association between word recall and healthcare utilisation. For example, we now observe a coefficient of -0.09 , which is considerable lower than 0.32 when we don't condition on health status. The results are also less statistically significant with the inclusion of SAH. For example, in column 3 we only observe statistical significance if our threshold is $p<0.1$, whereas the corresponding significance in Table 2 was $p<0.01$. We observe insignificant effects in both RE-NB and FE-OLS models. We conclude that this is the additional effect for people with good health - alongside good reported health, those with better word recall are less likely to be high users of health care utilisation. On the converse, those with bad health have additional use if they have lower than average word recall. People who are in better health make fewer visits than those who are in poorer health, at around 6-9 visits per year. Conversely, those who rate their health as poor can make up to 6 visits more than a similar individual in fair health.

Table 3 here

As discussed above, there are a number of possible groupings available to analyse here - groupings based upon observable characteristics of the countries in our sample. We discuss these results, in turn, below. For reasons of brevity, we present only the coefficients on key variables in Table 4. However, all models were run separately, and include the same regressors as included in Table 3 (i.e. we include $\mathrm{SAH})^{16}$. The first part of Table 4 looks at what association, if any, for those living in a country where the GP acts as a gatekeeper, of cognition on word recall/healthcare utilisation. In these models we include the number of words an individual recalls, along with a dummy variable that is equal to one if that individual lives in a GP-GK country, 0 otherwise. We also include the interaction

\footnotetext{
${ }^{16}$ Full output is available on request.
} 
of the GP-GK dummy with word recall. These latter two terms drop out of the FE specification due to collinearity. In columns $1-4$ the coefficient on word recall is negative and significant, as before, indicating better word recall may lead to fewer visits to a doctor. For these four specifications we also observe a negative and significant effect on living in a GP-GK country, implying that ceteris paribus an individual who lives in a GP-GK country makes fewer visits to an otherwise identical individual who lives in a country where the GP does not act as a GK.

In the FE models we run separate models for GK and non-GK countries. These are presented in columns 6 and 7. In both cases the coefficient on word recall is negative, but insignificant. Further, we cannot reject the hypothesis that these coefficients are the same, and hence we do not detect a significant variation between the two systems, which links back to the insignificant effects on the interaction term in columns $1-5$.

If the GP acts as a gatekeeper to further treatment, we may expect to see a larger affect when we consider GP visits only (and not along with hospital visits etc.), see second panel of Table 4. In this case, we typically see larger (in absolute value) coefficients indicating stronger affects. Interestingly, however, the interaction term is now positive and significant, indicating that the negative impacts of deteriorating word recall in terms of health care utilisation may be offset by living in a country where the GP acts as a GK.

The third panel of Table 4 looks at the affect that the funding of the health system has. Here, again, we observe a statistically significant and negative relationship between word recall and healthcare utilisation for the first five specifications. However, in the FE models (columns 6 and 7) there are no significant effects for either system. We further observe that individuals who live in countries where SHI contributions are necessary to fund healthcare use make fewer visits than like individuals who live in countries where the main healthcare funding is taxation. Again, this is not surprising - if there are personal costs associated with healthcare utilisation, then this may act as a potential barrier for people to use these services. If this barrier is not in place (i.e. taxation funded health systems) then individuals will be more willing to visit medical doctors more often. The fact that we condition on SAH makes these results more robust. The interaction effect is positive and significant, and this would tend to suggest that having poor word recall may be offset by living in a SHI funded country, when looking at healthcare use.

The differences between the two regimes are statistically significant until around 9 words are recalled, after which there is no evidence of a difference. However, very few individuals remember 9 or 10 word correctly. At the mean, there is a difference of approximately two $(=1.8)$ visits per year. 
In the final panel of Table 4, we consider what impact the provision of informal care has on the word recall/healthcare utilisation relationship. The major point of interest here is that we observe statistical insignificance on the word recall variable (except in column 6 , which is only significant at $\mathrm{p}<0.1$ ). This is the first instance where we have failed to find a significant relationship, and may indicate that the provision of informal care is an important factor in determining the relationship under consideration. At around 6 words the difference between the two country types becomes insignificant. At the mean, there is a difference of around one visit per year, but this is only just statistically significant.

\section{Table 4 here}

\section{Conclusion}

In this paper, we have demonstrated that there is a negative, and often statistically significant, relationship between cognitive impairment (when proxied by word recall) and healthcare utilisation (when measured by total visits to a medical doctor). To our knowledge, this is the first study that attempts to (i) identify this relationship and (ii) quantify the magnitude of the effect.

Given that governments are seeking ways to reduce their healthcare budgets, especially those that target the ageing population, and the fact that we have found an association between cognitive impairment and utilisation, one policy recommendation would be to implement measures (at a time before old age) that aim to reduce the dependence on health care resources by those with cognitive impairment. The implementation of integrated health and social care could aim to reduce this reliance on primary and secondary care, and ensure social care is provided for those who wish to live at home. Such a policy would also have potential for further reducing the health care costs associated with dementia. 


\section{References}

Bonsang, Eric, Stéphane Adam, and Sergio Perelman. 2012. 'Does Retirement Affect Cognitive Functioning?'. Journal of Health Economics 31 (3): 490-501. doi:10.1016/j.jhealeco.2012.03.005.

Cameron, A. Colin, and Pravin K. Trivedi. 2005. Microeconometrics: Methods and Applications. Cambridge ; New York: Cambridge University Press.

Christensen, H., A. E. Korten, A. F. Jorm, A. S. Henderson, P. A. Jacomb, B. Rodgers, and A. J. Mackinnon. 1997. 'Education and Decline in Cognitive Performance: Compensatory but Not Protective'. International Journal of Geriatric Psychiatry 12 (3): 323-30. doi:10.1002/(SICI)10991166(199703)12:3<323::AID-GPS492>3.0.CO;2-N.

Evans, Denis A., Laurel A. Beckett, Marilyn S. Albert, Liesi E. Hebert, Paul A. Scherr, H. Harris Funkenstein, and James O. Taylor. 1993. 'Level of Education and Change in Cognitive Function in a Community Population of Older Persons'. Annals of Epidemiology 3 (1): 71-77. doi:10.1016/10472797(93)90012-S.

Greene, W. H. 2008. Econometric Analysis. 6th edition. Upper Saddle River, N.J.: Prentice Hall.

Grossman, Michael. 1972. 'On the Concept of Health Capital and the Demand for Health'. Journal of Political Economy 80 (2): 223-55.

Hausman, Jerry A. 1978. 'Specification Tests in Econometrics'. Econometrica: Journal of the Econometric Society 46: 1251-71.

Jack, William. 1999. Principles of Health Economics for Developing Countries. World Bank Publications.

Kawamura, T., Umemura, T. and N. Hotta (2012) Cognitive impairment in diabetic patients: can diabetic control prevent cognitive decline? Journal of Diabetes Investigation, 3(5):413-423. 
Mazzonna, Fabrizio, and Franco Peracchi. 2012. 'Ageing, Cognitive Abilities and Retirement'.

European Economic Review 56 (4): 691-710. doi:10.1016/j.euroecorev.2012.03.004.

Singh-Manoux, Archana, Mika Kivimaki, M. Maria Glymour, Alexis Elbaz, Claudine Berr, Klaus P. Ebmeier, Jane E.

World Alzheimer Report. 2012. Alzheimer's Disease International. http://www.alz.co.uk/research/world-report-2012. 
Tables

Table 1: Selected Summary Statistics

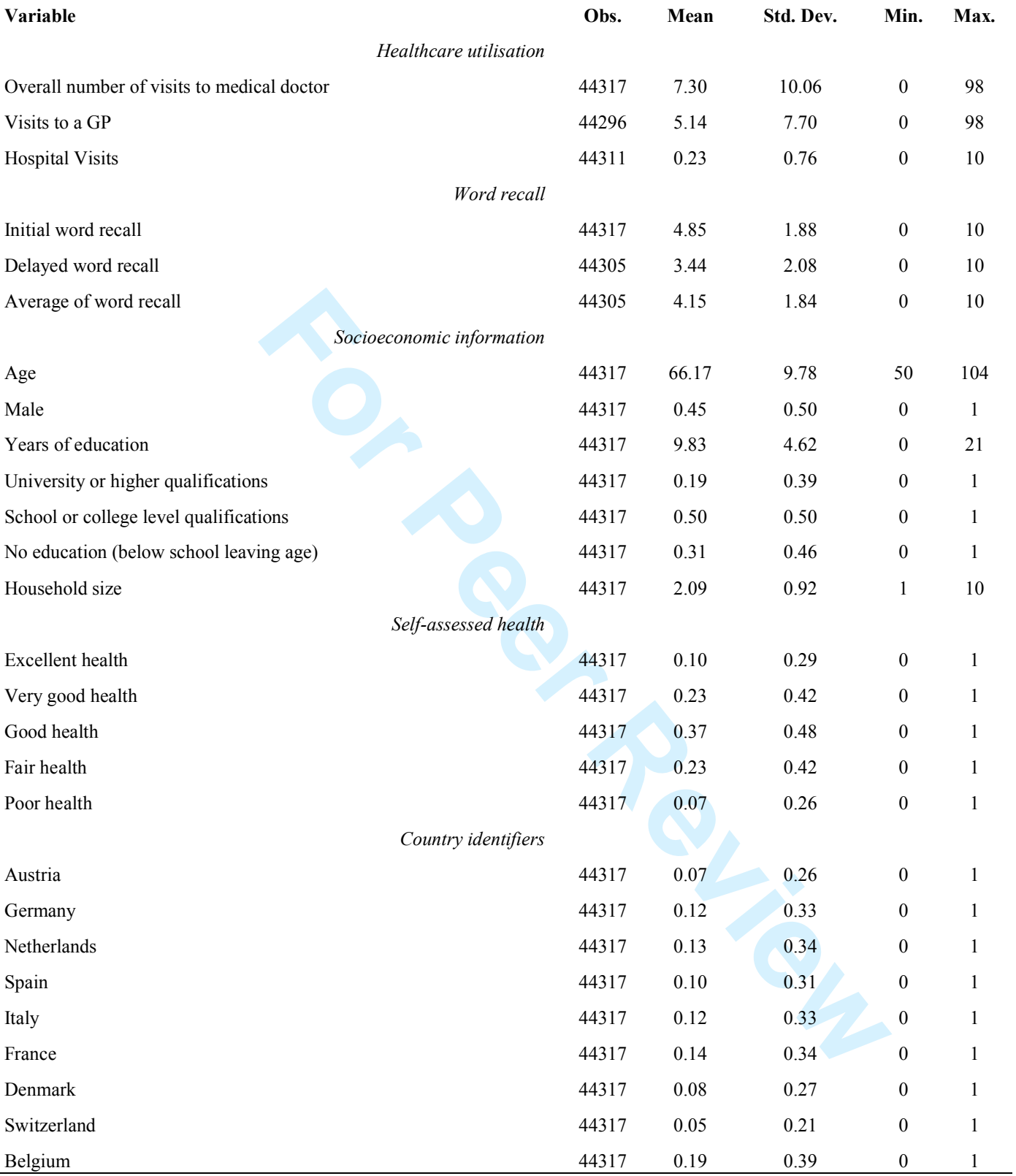


1

2

3

4

5

6

7

8

9

10

11

12

13

14

15

16

17

18

19

20

21

22

23

24

25

26

27

28

29

30

31

32

33

34

35

36

37

38

39

40

41

42

43

44

45

46

47

48

49

50

51

52

53

54

55

56

57

58

59

60

Table 2: Word recall and all utilisation

\begin{tabular}{|c|c|c|c|c|c|c|}
\hline & (1) & (2) & (3) & (4) & (5) & (6) \\
\hline & Pooled OLS & $\begin{array}{l}\text { Pooled NB } \\
\text { Coeff. }\end{array}$ & $\begin{array}{l}\text { Pooled NB } \\
\text { Marg. Eff. }\end{array}$ & RE OLS & $\begin{array}{l}\text { RE NB } \\
\text { Coeff. }\end{array}$ & $\begin{array}{l}\text { FE OLS } \\
\text { Coeff. }\end{array}$ \\
\hline Number of words recalled & $\begin{array}{l}-0.324 * * * \\
(0.0352)\end{array}$ & $\begin{array}{l}-0.0406^{* * *} \\
(0.00457)\end{array}$ & $\begin{array}{l}-0.296 * * * \\
(0.0337)\end{array}$ & $\begin{array}{l}-0.235^{* * *} \\
(0.0291)\end{array}$ & $\begin{array}{l}-0.0107 * * * \\
(0.00273)\end{array}$ & $\begin{array}{l}-0.101 * * \\
(0.0393)\end{array}$ \\
\hline Observations & 44317 & 44317 & 44317 & 44317 & 44317 & 44317 \\
\hline
\end{tabular}

Standard errors in parentheses (for pooled models standard errors are clustered at the individual level,

for marginal effects standard errors are calculated using the delta method). ${ }^{*} \mathrm{p}<0.10,{ }^{* *} \mathrm{p}<0.05,{ }^{* * *} \mathrm{p}<0.01$

The same covariates are used as in Table 4(b), with the exception of SAH.

15

Editorial Office, Dept of Economics, Warwick University, Coventry CV4 7AL, UK 
Table 3: Pooled sample results controlling for SAH

\begin{tabular}{|c|c|c|c|c|c|c|}
\hline & (1) & (2) & (3) & (4) & (5) & (6) \\
\hline & Pooled OLS & Pooled NB & Marg. Eff. & RE OLS & RE NB & FE OLS \\
\hline \multirow[t]{2}{*}{ Number of words recalled } & $-0.0895 * * *$ & $-0.00749^{*}$ & $-0.0549 *$ & $-0.101 * * *$ & -0.00198 & -0.0623 \\
\hline & $(0.0320)$ & $(0.00409)$ & $(0.0300)$ & $(0.0280)$ & $(0.00260)$ & $(0.0387)$ \\
\hline \multirow[t]{2}{*}{ Age } & $0.0365^{* * *}$ & $0.00778 * * *$ & $0.0570 * * *$ & $0.0444 * * *$ & $0.0102 * * *$ & $0.0600 * * *$ \\
\hline & $(0.00645)$ & $(0.000813)$ & $(0.00595)$ & $(0.00620)$ & $(0.000566)$ & $(0.0174)$ \\
\hline \multirow[t]{2}{*}{ Male } & $-0.590 * * *$ & $-0.101 * * *$ & $-0.742 * * *$ & $-0.623 * * *$ & $-0.113^{* * *}$ & \\
\hline & $(0.101)$ & $(0.0137)$ & $(0.101)$ & $(0.114)$ & $(0.0104)$ & \\
\hline \multirow[t]{2}{*}{ University or above qualifications } & -0.137 & 0.00161 & 0.0118 & $-0.373 * *$ & 0.0202 & \\
\hline & $(0.156)$ & $(0.0223)$ & $(0.164)$ & $(0.186)$ & $(0.0169)$ & \\
\hline \multirow[t]{2}{*}{ School or college qualifications } & $-0.345^{* *}$ & $-0.0305^{*}$ & $-0.223^{*}$ & $-0.468 * * *$ & -0.0115 & \\
\hline & $(0.136)$ & $(0.0168)$ & $(0.123)$ & $(0.146)$ & $(0.0132)$ & \\
\hline \multirow[t]{2}{*}{ Household Size } & $-0.310^{* * *}$ & $-0.0387 * * *$ & $-0.284 * * *$ & $-0.278^{* * *}$ & $-0.0321 * * *$ & -0.137 \\
\hline & $(0.0624)$ & $(0.00836)$ & $(0.0613)$ & $(0.0598)$ & $(0.00563)$ & $(0.106)$ \\
\hline \multirow[t]{2}{*}{ Excellent health } & $-6.861 * * *$ & $-1.186^{* * *}$ & $-8.696^{* * *}$ & $-5.917 * * *$ & $-0.942 * * *$ & $-3.459 * * *$ \\
\hline & $(0.152)$ & $(0.0306)$ & $(0.237)$ & $(0.180)$ & $(0.0194)$ & $(0.253)$ \\
\hline \multirow[t]{2}{*}{ Very good health } & $-5.689^{* * *}$ & $-0.815 * * *$ & $-5.975 * * *$ & $-4.820 * * *$ & $-0.596 * * *$ & $-2.763 * * *$ \\
\hline & $(0.139)$ & $(0.0182)$ & $(0.145)$ & $(0.134)$ & $(0.0128)$ & $(0.185)$ \\
\hline \multirow[t]{2}{*}{ Good health } & $-3.890^{* * *}$ & $-0.463 * * *$ & $-3.392 * * *$ & $-3.251 * * *$ & $-0.335^{* * *}$ & $-1.899 * * *$ \\
\hline & $(0.135)$ & $(0.0150)$ & $(0.114)$ & $(0.116)$ & $(0.0102)$ & $(0.149)$ \\
\hline \multirow[t]{2}{*}{ Poor health } & $5.901 * * *$ & $0.432 * * *$ & $3.164 * * *$ & $5.185^{* * *}$ & $0.271^{* * *}$ & $3.669^{* * *}$ \\
\hline & $(0.348)$ & $(0.0227)$ & $(0.171)$ & $(0.186)$ & $(0.0144)$ & $(0.240)$ \\
\hline \multirow[t]{2}{*}{ Constant } & $9.925 * * *$ & $2.043^{* * *}$ & & $9.112 * * *$ & & $5.344 * * *$ \\
\hline & $(0.637)$ & $(0.0792)$ & & $(0.582)$ & & $(1.265)$ \\
\hline Observations & 44317 & 44317 & 44317 & 44317 & 44317 & 44317 \\
\hline
\end{tabular}

Standard errors in parentheses (for pooled models standard errors are clustered at the individual level,

for marginal effects standard errors are calculated using the delta method). ${ }^{*} \mathrm{p}<0.10,{ }^{* *} \mathrm{p}<0.05,{ }^{* * *} \mathrm{p}<0.01$

We also include country identifiers, although they are omitted here for reasons of space. 
Table 4: Results by Various Country Groupings

\begin{tabular}{|c|c|c|c|c|c|c|c|}
\hline & (1) & (2) & (3) & (4) & (5) & (6) & (7) \\
\hline & Pooled OLS & Pooled NB & Marg. Eff. & RE OLS & $\begin{array}{c}\text { RE NB } \\
\text { Coefficient }\end{array}$ & $\begin{array}{c}\text { FE OLS } \\
\text { (indicator=0) }\end{array}$ & $\begin{array}{c}\text { FE OLS } \\
\text { (indicator=1) }\end{array}$ \\
\hline \multicolumn{8}{|l|}{ Gatekeepr: All visits } \\
\hline \multirow[t]{2}{*}{ Number of words recalled } & $-0.195 * * *$ & $-0.0144^{* * *}$ & $-0.106 * * *$ & $-0.184 * * *$ & -0.00539 & -0.0750 & -0.0498 \\
\hline & $(0.0498)$ & $(0.00548)$ & $(0.0402)$ & $(0.0410)$ & $(0.00371)$ & $(0.0589)$ & $(0.0514)$ \\
\hline \multirow[t]{2}{*}{ GP Gatekeeper } & $-1.595 * * *$ & $-0.132 * * *$ & $-0.968 * * *$ & $-1.621 * * *$ & $-0.196 * * *$ & & \\
\hline & $(0.350)$ & $(0.0376)$ & $(0.275)$ & $(0.283)$ & $(0.0256)$ & & \\
\hline \multirow[t]{2}{*}{ Interaction } & 0.0503 & -0.0102 & -0.0745 & 0.0520 & 0.00163 & & \\
\hline & $(0.0611)$ & $(0.00713)$ & $(0.0523)$ & $(0.0519)$ & $(0.00475)$ & & \\
\hline \multicolumn{8}{|c|}{ Gatekeeper: Visits to GP only } \\
\hline \multirow[t]{2}{*}{ Number of words recalled } & $-0.299 * * *$ & $-0.0418^{* * *}$ & $-0.216 * * *$ & $-0.239 * * *$ & $-0.0228 * * *$ & -0.0675 & 0.00636 \\
\hline & $(0.0403)$ & $(0.00580)$ & $(0.0300)$ & $(0.0313)$ & $(0.00400)$ & $(0.0414)$ & $(0.0388)$ \\
\hline \multirow[t]{2}{*}{ GP Gatekeeper } & $-1.538 * * *$ & $-0.205 * * *$ & $-1.058 * * *$ & $-1.520 * * *$ & $-0.272 * * *$ & & \\
\hline & $(0.291)$ & $(0.0395)$ & $(0.204)$ & $(0.219)$ & $(0.0275)$ & & \\
\hline \multirow[t]{2}{*}{ Interaction } & $0.127 * *$ & 0.00774 & 0.0399 & $0.118^{* * *}$ & $0.0196^{* * *}$ & & \\
\hline & $(0.0497)$ & $(0.00742)$ & $(0.0383)$ & $(0.0398)$ & $(0.00511)$ & & \\
\hline \multicolumn{8}{|l|}{ Funding: All visits } \\
\hline \multirow[t]{2}{*}{ Number of words recalled } & $-0.182 * * *$ & $-0.0179 * * *$ & $-0.132 * * *$ & $-0.168 * * *$ & -0.000385 & -0.0576 & -0.0673 \\
\hline & $(0.0373)$ & $(0.00457)$ & $(0.0337)$ & $(0.0326)$ & $(0.00297)$ & $(0.0470)$ & $(0.0680)$ \\
\hline \multirow[t]{2}{*}{ SHI Funded } & $-2.369 * * *$ & $-0.311 * * *$ & $-2.280 * * *$ & $-2.007 * * *$ & $-0.220 * * *$ & & \\
\hline & $(0.355)$ & $(0.0456)$ & $(0.337)$ & $(0.323)$ & $(0.0306)$ & & \\
\hline \multirow[t]{2}{*}{ Interaction } & $0.245^{* * *}$ & $0.0228 * * *$ & $0.168 * * *$ & $0.172 * * *$ & 0.00552 & & \\
\hline & $(0.0625)$ & $(0.00836)$ & $(0.0615)$ & $(0.0572)$ & $(0.00546)$ & & \\
\hline \multicolumn{8}{|c|}{ Informal Care: All visits } \\
\hline \multirow[t]{2}{*}{ Number of words recalled } & 0.0338 & -0.00215 & -0.0158 & -0.0241 & -0.00349 & $-0.113 * *$ & -0.0294 \\
\hline & $(0.0467)$ & $(0.00655)$ & $(0.0480)$ & $(0.0445)$ & $(0.00421)$ & $(0.0571)$ & $(0.0511)$ \\
\hline \multirow[t]{2}{*}{ High Informal Care } & $2.276^{* * *}$ & $0.228 * * *$ & $1.670 * * *$ & $1.897 * * *$ & $0.0461^{*}$ & & \\
\hline & $(0.326)$ & $(0.0394)$ & $(0.290)$ & $(0.286)$ & $(0.0264)$ & & \\
\hline \multirow[t]{2}{*}{ Interaction } & $-0.237 * * *$ & $-0.0185^{* *}$ & $-0.135^{* *}$ & $-0.154^{* * *}$ & 0.00341 & & \\
\hline & $(0.0578)$ & $(0.00752)$ & $(0.0551)$ & $(0.0532)$ & $(0.00495)$ & & \\
\hline Observations & 44317 & 44317 & 44317 & 44317 & 44317 & 18889 & 25428 \\
\hline \multicolumn{8}{|c|}{$\begin{array}{l}\text { effects standard errors are calculated using the delta method). }{ }^{*} \mathrm{p}<0.10,{ }^{* *} \mathrm{p}<0.05, * * * \mathrm{p}<0.01 \\
\text { Each of the above is run as a separate regression with the same controls as above. }\end{array}$} \\
\hline
\end{tabular}


Figures

Figure 1: The distribution of healthcare utilisation and word recall variables

(a) Healthcare utilisation
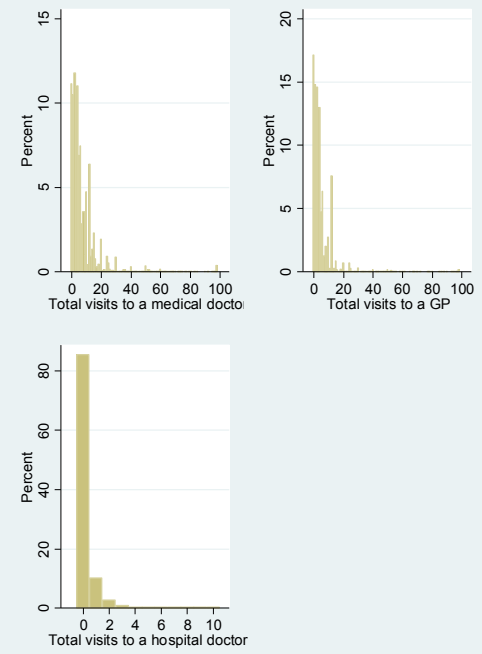

(b) Word recall
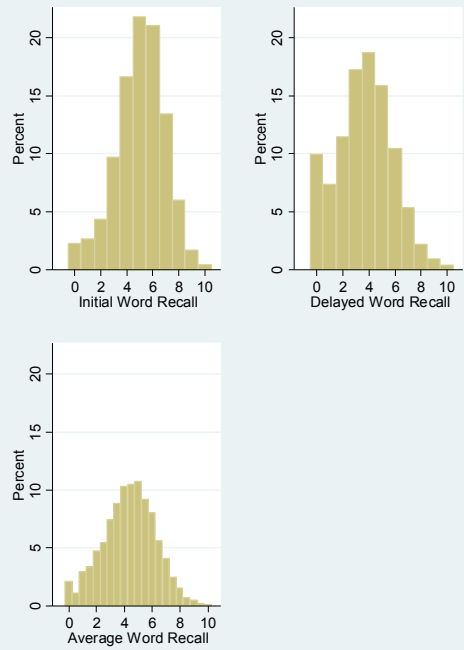

Figure 2: Trajectories of word recall across age cohorts
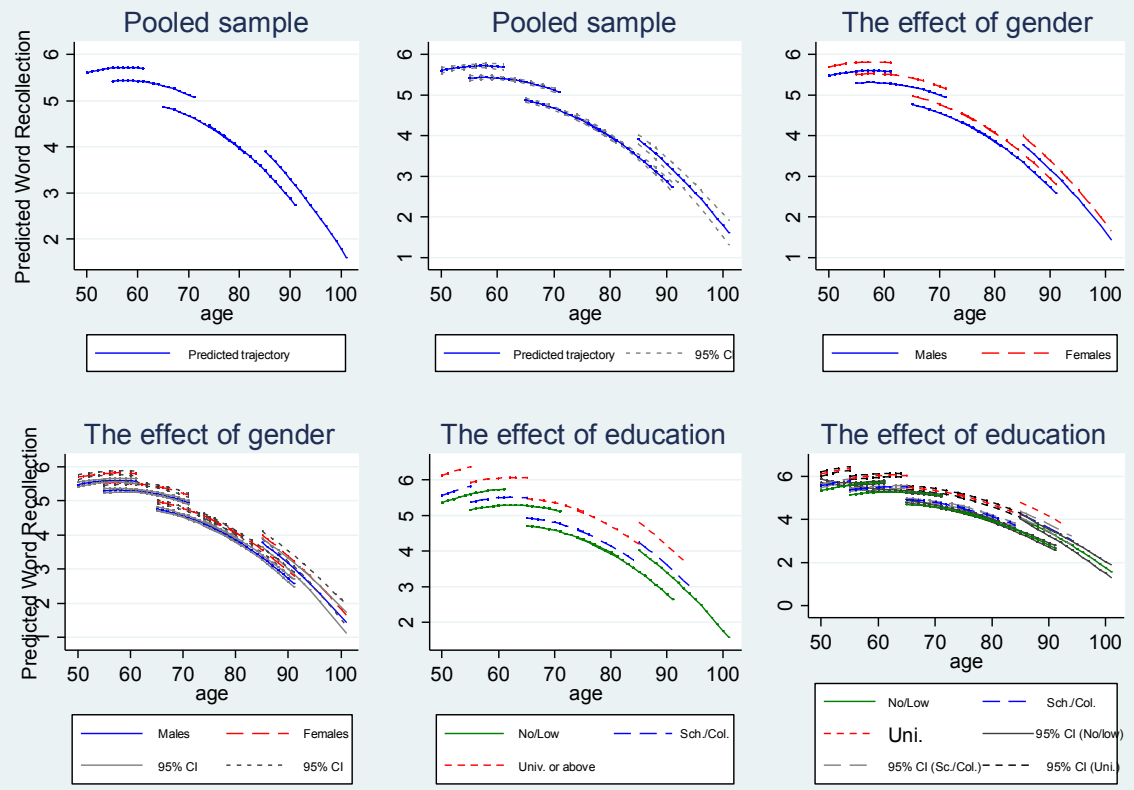